\title{
A Voltammetric Biosensor Based on Glassy Carbon Electrodes Modified with Single-Walled Carbon Nanotubes/Hemoglobin for Detection of Acrylamide in Water Extracts from Potato Crisps
}

\author{
Agnieszka Krajewska, Jerzy Radecki and Hanna Radecka*
}

Institute of Animal Reproduction and Food Research, The Polish Academy of Sciences, Tuwima 10, 10-747 Olsztyn, Poland

* Author to whom correspondence should be addressed; E-mail: hanna.radecka@ pan.olsztyn.pl, Tel.: +48 895234613

Received: 1 August 2008; in revised form: 12 September 2008 / Accepted: 18 September 2008 / Published: 23 September 2008

\begin{abstract}
The presence of toxic acrylamide in a wide range of food products such as potato crisps, French fries or bread has been confirmed by Swedish scientists from Stockholm University. The neurotoxicity, possible carcinogenicity of this compound and its metabolites compels us to control them by quantitative and qualitative assays. Acrylamide forms adduct with hemoglobin $(\mathrm{Hb})$ as a result of the reaction the $-\mathrm{NH}_{2}$ group of the $\mathrm{N}$ terminal valine with acrylamide. In this work we present the use of glassy carbon electrodes coated with single-walled carbon nanotubes (SWCNTs) and Hb for voltammetric detection of acrylamide in water solutions. The electrodes presented a very low detection limit $\left(1.0 \times 10^{-9} \mathrm{M}\right)$. The validation made in the matrix obtained by water extraction of potato crisps showed that the electrodes presented are suitable for the direct determination of acrylamide in food samples.
\end{abstract}

Keywords: Acrylamide, hemoglobin, SWCNTs, OSWV, potato crisps

\section{Introduction}

Acrylamide is a well known neurotoxin and potential carcinogen [1-3]. High levels of this compound have been found in potato crisps, French fries and several other common foods [1, 4, 5]. The first such report was announced by scientists from Stockholm University in 2002 [1]. Acrylamide 
is formed in the reaction between reducing sugars such as glucose and the amino acid asparagine. The Maillard reaction mechanism has been proposed to account its formation in high starch foods during cooking at high temperatures [6-8]. Among analytical methods used for determination of acrylamide levels, expensive and time-consuming chromatographic techniques such as GC-MS [9], GC-MS-MS [10], HPLC-MS [11] and LC-MS-MS [5] predominate. Preparation of food samples for analysis involves extraction using water or methanol and the clean-up step typically consists of a combination of several solid-phase extractions. GC-MS often needs an additionally laborious bromination step to form a more volatile acrylamide derivative and increase the selectivity of the determination. Only a few examples using different techniques for detection of this toxic compound exist. Ignatov and co-workers prepared a biosensor in which respiratory activity of microbial cells was used for detection of acrylamide [12]. Kleefisch and co-workers reported a sensor in which acrylamide was detected at a gas-solid interface using an 'electronic nose'-type quartz crystal microbalance (QCM) sensor covered with a tetralactam active layer [13].

It is known that acrylamide can create adducts with hemoglobin [1, 2, 14]. Hemoglobin $(\mathrm{Hb})$ is the iron-containing oxygen-transport metalloprotein present in the red blood cells of vertebrates. Human $\mathrm{Hb}(\mathrm{MW}=64,500)$ is an assembly of four globular protein subunits non-covalently bound to each other. Interactions between these subunits results in the allosteric properties of this protein. Each of the four subunits is composed of a protein chain tightly associated with a non-protein heme group, which is located in crevices near the surface of the molecule. These four iron-heme prosthetic groups are responsible for electroactivity of hemoglobin undergoing the reversible conversion of $\mathrm{Fe}$ (III) to $\mathrm{Fe}$ (II).

$\mathrm{The} \mathrm{Hb}$ is susceptible to both reversible and irreversible modification: the sixth position of the iron can be spontaneously occupied by small ligands like oxygen, $\mathrm{CO}$ or $\mathrm{CN}^{-}$. The $N$-terminal amino acid of the $\beta$ chain reacts spontaneously with glucose via an instable Schiffs base to ketoimine or fructose. The cysteine residues of the $\beta$ chains are highly reactive and react with $\mathrm{NO}$ and other $\mathrm{SH}$ blocking reagents [15].

It is known that acrylamide and related conjugated vinyl compounds, undergo Michael-type nucleophilic addition reactions of amino $\left(\mathrm{NH}_{2}\right)$ and sulfhydryl $(\mathrm{SH})$ groups of amino acids, peptides and proteins to their double bonds [2]. Investigations showed that acrylamide-Hb adducts are formed as a result of the reaction between the $\alpha-\mathrm{NH}_{2}$ group of the $N$-terminal valine of $\mathrm{Hb}$ with acrylamide $[1,2]$. Therefore, hemoglobin can serve as useful biomarker of human exposure to acrylamide. The tracing of background exposure to acrylamide through biomarker measurements were conducted using GC-MSMS method in the negative ion/chemical ionization mode [16] or with GC-MS [17]. Stobiecka and coworkers introduced a voltammetric sensor based on the reaction of hemoglobin with acrylamide [14]. This reaction led to the hemoglobin-acrylamide adducts formation, what alters the electroactivity of hemoglobin.

The adsorption of biomolecules directly onto the naked surfaces of bulk materials may frequently result in their denaturation and loss of bioactivity. The adsorption of such biomolecules onto the surface of nanoparticles can retain their bioactivity because of the biocompatibility of nanoparticles [18]. Carbon nanotubes (CNT) can serve as amplification platforms ('carriers') when loaded with numerous signal-generating molecules [19]. The SWCNT-modified electrode showed promising electrocatalytic behavior toward several biomolecules, such as dopamine, epinephrine and ascorbic 
acid [20]. Such modified electrodes might be used in biosensors to study the electrochemistry of biosystems. The subtle electronic properties suggest that CNT have the ability to promote electron transfer in electrochemical reactions, what has been documented in connection to important biomolecules such as hemoglobin, horseradish peroxidase and glucose oxidase [21].

In the literature we can find many examples of hemoglobin immobilization on the surfaces of gold, glassy carbon, pyrolytic graphite or carbon paste electrodes. Many procedures involve gold nanoparticles [22-28], single- and multi-wall carbon nanotubes [21, 29-32], whisker-like carbon composites [33].

Yin and co-workers reported biosensors in which hemoglobin, horseradish peroxidase and glucose oxidase were immobilized on the surface of carbon nanotubes modified glassy carbon electrodes (Nafion-Hb-CNT/GCE). The results obtained using cyclic voltammetry indicated that the redox protein and enzyme underwent effective and stable direct electron transfer reaction. The average value of the formal redox potential $E^{0}$, for $\mathrm{Hb}$ was $-0.343 \pm 0.001 \mathrm{~V}$ (vs. SCE, pH 6.9) [21].

$\mathrm{R}$. Zhang and co-workers showed that $\mathrm{Hb}$ can be coupled to acid-treated multiwall carbon nanotubes (MWCNTs) in the presence of 1-ethyl-3-(3-dimethylaminopropyl) carbodiimide (EDC) and assembled as Hb-CNT composites on glassy carbon electrodes surfaces [29]. The electrochemical response of such prepared electrodes was compared with response of electrodes modified without using of EDC. These results indicate that use of EDC can accelerate the direct electron transfer of $\mathrm{Hb}$ effectively. Redox peaks were detected at -136 and $-300 \mathrm{mV}$ (vs. SCE, pH 5.0) and the peak current ratio at these potentials was about 1 . When procedure without EDC was used, redox peaks detected were located in similar positions but electrochemical response of $\mathrm{Hb}$ was considerably lower.

Y. Zhang and co-workers investigated direct electrochemistry of hemoglobin immobilized on the DDAB/SWCNTs film modified gold electrode [31]. The immobilized Hb displayed a couple of redox peaks with the formal potential of about $129 \mathrm{mV}$ (vs SCE, pH 7.0).

In this paper we present the use of glassy carbon electrodes coated with SWCNTs and Hb. In all experiments single-walled nanotubes (SWCNTs) were used as more stable and possessing less structural defects then MWNTs. The tubes performed a role of element promoting the electron transfer of $\mathrm{Hb}$ electrochemical reaction and ensuring its bioactivity. Hemoglobin was applied as an electroactive element able to react with acrylamide in vivo and on the surface of electrode. Such prepared electrodes were used for voltammetric detection of this analyte in water solution.

\section{Materials and Methods}

\subsection{Materials}

Hemoglobin human $(\mathrm{Hb})$, acrylamide and potassium hexacyanoferrate(II) trihydrate were purchased from Sigma-Aldrich (Poznań, Poland). Acetic acid, zinc sulphate heptahydrate, sodium chloride, sodium hydroxide and hexane were obtained from POCh (Gliwice, Poland). Single-walled carbon nanotubes (SWCNTs) were purchased from CarboLex (Lexington, USA). Carrez I solution was prepared by dissolving potassium hexacyanoferrate (II) trihydrate $(144 \mathrm{~g})$ in deionized water $(500 \mathrm{~mL})$. Carrez II solution was prepared by dissolving zinc sulphate heptahydrate $(288 \mathrm{~g})$ in deionized water 
$(500 \mathrm{~mL})$. All aqueous solutions were prepared using freshly deionized water $(18.2 \mathrm{M} \Omega \mathrm{cm}$ specific resistivity) obtained with a Simplicity 185 Water System (Millipore, Molsheim, France).

\subsection{Preparation of electrodes}

Glassy carbon electrodes (3.0 mm dia.) purchased from Bioanalytical Systems (BAS, West Lafayette, USA) were cleaned mechanically by polishing with wet 0.3 and $0.05 \mu \mathrm{m}$ alumina slurry (Alpha and Gamma Micropolish; Buehler, Lake Bluff, USA) on microcloth pad (BAS) and by sonicating in water $\left(30 \mathrm{sec}\right.$.). Then the electrodes were dipped in $0.5 \mathrm{M} \mathrm{H}_{2} \mathrm{SO}_{4}$ solution and sweeping the potential between $-300 \mathrm{mV}$ and $+1400 \mathrm{mV}$ (versus a $\mathrm{Ag} / \mathrm{AgCl}$ reference electrode) with scan rate of $100 \mathrm{mVs}^{-1}$.

\subsection{Purification of SWCNTs}

Single-walled carbon nanotubes (SWCNTs, $10 \mathrm{mg}$ ) were purified by sonication for 30 min in a mixture of concentrated sulfuric and nitric acids $\left(3: 1 \mathrm{HNO}_{3} / \mathrm{H}_{2} \mathrm{SO}_{4}, 10 \mathrm{~mL}\right)$ and heating to reflux for 1 h. Afterwards, the resultant nanotubes were filtered and thoroughly washed using doubly distilled water and then dispersed in ultrapure water $(1 \mathrm{~mL})$.

\subsection{Modification of electrodes}

After the purification step the resulting solution of SWCNTs in water was diluted five times and 5 $\mu \mathrm{L}$ was dropped on the surface of glassy carbon electrode and left to dry at $4^{\circ} \mathrm{C}$. Then $10 \mathrm{mg} / \mathrm{mL}$ hemoglobin solution in $0.2 \mathrm{M}$ acetate buffer containing $0.05 \mathrm{M} \mathrm{NaCl} \mathrm{pH}=5.0(5 \mu \mathrm{L})$ was dropped on the electrode surface and again left to dry at $4^{\circ} \mathrm{C}$. Then electrodes were stored on air at $4^{\circ} \mathrm{C}$ till use.

\subsection{Electrochemical measurements}

All electrochemical measurements were performed with an AutoLab potentiostat-galvanostat (Eco Chemie, Utrecht, Netherlands) with a three electrode configuration. Potentials were measured versus the $\mathrm{Ag} / \mathrm{AgCl}$ reference electrode obtained from Bioanalytical Systems (BAS) West Lafayette, USA. $\mathrm{Ag} / \mathrm{AgCl}$ wire was placed in a glass tube filled with $3 \mathrm{M} \mathrm{NaCl}$. The tube was closed with a vycor plug to protect of the inner solution from direct contact with the sample. A platinum wire was used as the auxiliary electrode. Cyclic voltammetry (CV) was performed and potential was cycled from +400 to $400 \mathrm{mV}$ with scan rate $100 \mathrm{mV} / \mathrm{s}$ for GCE coated with SWCNT and Hb (GCE/SWCNT/Hb). Osteryoung square wave voltammetry (OSWV) was performed in the same potential window with step potential of $1 \mathrm{mV}$, a square-wave frequency of $100 \mathrm{~Hz}$, and amplitude of $25 \mathrm{mV}$. The dependence of the sensor response on the concentration of analytes was expressed as the currents at the peak potential in OSWV measured in a solution containing no analyte. The electrolyte compositions for the measurements was as follows: $0.05 \mathrm{M} \mathrm{NaCl}+0.2 \mathrm{M}$ acetate buffer, $\mathrm{pH}$ 5.0. 


\subsection{Preparation of potato crisp water extracts}

Crushed potato crisps ( $40 \mathrm{~g}$ ) were mixed in a mortar to obtain a homogeneous sample. The obtained powder was added to deionized water $(400 \mathrm{~mL})$ and the sample was stored for $20 \mathrm{~min}$ for swelling. After this incubation time, the sample was shaken for $1 \mathrm{~h}$ at $60{ }^{\circ} \mathrm{C}$ (Ika, HS-B20 digital) and then centrifuged for about $20 \mathrm{~min}$ at 4,500 rpm (MPW Med. instruments, MPW 350R). The supernatant solution was defatted by extraction with hexane. The obtained aqueous solution was purified by adding Carrez I and Carrez II (10 mL, see section 2.1). The supernatant was subsequently filtered. Such a prepared matrix was diluted 100-fold before electrochemical measurements. After that a suitable amount of concentrated acetic acid and $\mathrm{NaCl}$ were added to obtained concentrations $0.2 \mathrm{M}$ and $0.05 \mathrm{M}$, respectively. $\mathrm{pH}$ of the final solution was adjusted to $\mathrm{pH} 5.0$ with $1 \mathrm{M} \mathrm{NaOH}$.

\section{Results and Discussion}

\subsection{Characterisation of GCE/SWCNT/Hb electrodes.}

In this work we report an investigation concerning the electrochemistry of GCE electrodes modified with SWCNTs and $\mathrm{Hb}$. The carbon nanotubes were used after consideration to their unique structural, mechanical and electronic properties [34]. The nanotubes were chemically treated with strong acids. This treatment not only purified them, but also reduced their length and led to the formation of carboxylic and phenolic groups at the nanotube's ends [35-37]. The acid treated SWCNTs were deposited onto surfaces of glassy carbon electrodes and than $\mathrm{Hb}$ was immobilized by dropping on SWCNT/GCE surface. The base of detection of acrylamide by proposed biosensor is the reaction of $\mathrm{Hb}-\mathrm{NH}_{2}$ groups with the analyte. Because of this EDC was not used in the procedure of biosensor preparation. Involving $\mathrm{Hb}-\mathrm{NH}_{2}$ groups in the reaction with SWCNT-COOH could decrease the yield of the $\mathrm{Hb}$-acrylamide adduct formation.

The investigated GCE/SWCNT/Hb electrodes displayed a quasi-reversible electrochemical reaction in measured solution $\mathrm{pH}=5.0$ (Figure 1). The cathodic and anodic peak potential were located at $E_{\text {cat }}=72 \mathrm{mV}$ and $E_{\mathrm{an}}=141 \mathrm{mV}$, respectively. The difference between the cathodic and anodic peaks potential $\left(\Delta \mathrm{E}_{\mathrm{p}}\right)$ was about $69 \mathrm{mV}$. The formal potential, estimated as the average of reduction and oxidation peak potentials, was about $E^{0}=107 \mathrm{mV}$. Cathodic $I_{\mathrm{p}, \mathrm{c}}[\mu \mathrm{A}]$ and anodic $I_{\mathrm{p}, \mathrm{a}}[\mu \mathrm{A}]$ peaks currents were linearly dependent on scan rate $v$, ranging from 0.01 to $9.0 \mathrm{~V} / \mathrm{s}\left(\mathrm{y}=-8.008 \mathrm{x}-0.235, \mathrm{R}^{2}=0.996\right.$ for $I_{\mathrm{p}, \mathrm{c}}$ and $\mathrm{y}=7.406 \mathrm{x}+0.170, \mathrm{R}^{2}=0.998$ for $I_{\mathrm{p}, \mathrm{a}}$ ) (Fig. 1). This indicates that redox reaction is not a diffusion-controlled process, but a surface-controlled one, as expected for an immobilized system [38].

Similar modification procedure was used by Qi and co-workers [30]. Acid-treated MWCNTs suspension in DMF was cast on the surface of glassy carbon electrode. After solvent evaporation $\mathrm{Hb}$ solution was dropped onto the surface of MWCNT/GCE. In the cyclic voltammograms of MWCNT/GCE a pair of redox peaks appeared at $+67 \mathrm{mV}$ and $+110 \mathrm{mV}$ (vs. $\mathrm{Ag} / \mathrm{AgCl}, \mathrm{pH}$ 5.4) and come from carboxylic groups of the functionalized MWNTs [20]. With Hb/MWCNT/GCE these peaks disappeared and a pair of new redox peaks appeared at -195 and $-288 \mathrm{mV}$ (measured in solution $\mathrm{pH}$ 5.4) which came from $\mathrm{Hb}$. The formal potential was $-240 \mathrm{mV}$. The disappearance of peaks at positive 
potentials after $\mathrm{Hb}$ immobilization was explain by interactions of $\mathrm{Hb}$ with carboxylic acid groups of the functionalized MWCNT.

Figure 1. (A) The $\mathrm{CV}$ curves for GCE/SWCNT/Hb measured in solution containing $\mathrm{NaCl}$ $0.05 \mathrm{M}$ and acetate buffer $0.2 \mathrm{M} \mathrm{pH}=5.0 \mathrm{vs}$ scan rates: 0.01, 0.02, 0.03, 0.04, 0.05, 0.075, $0.1,0.2,0.3,0.4,0.5,0.75,1.0,2.0,3.0,5.0,9.0 \mathrm{~V} / \mathrm{s}$. (B) Linear relationship between cathodic and anodic peak current $v s$. scan rate.

\section{A}

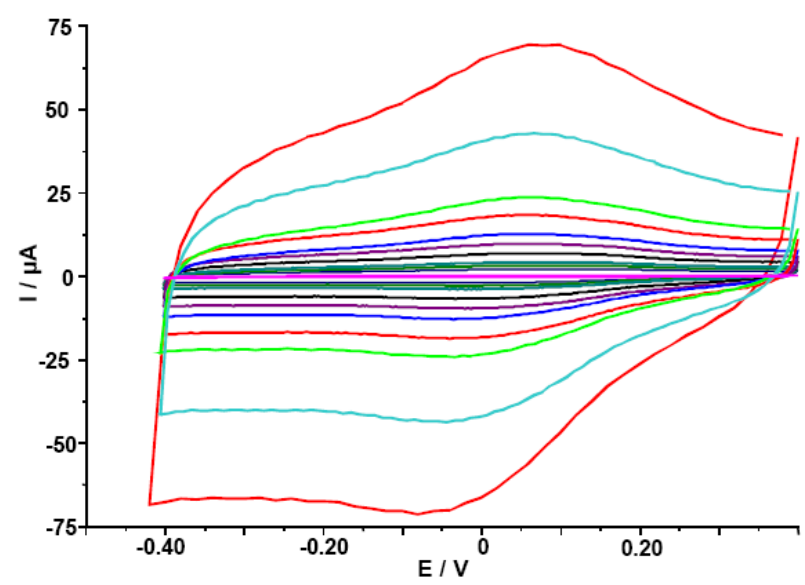

B

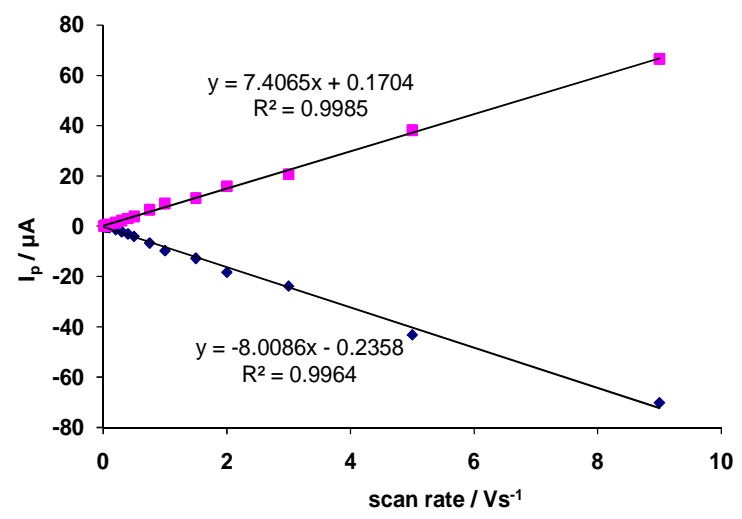

Results reported in this paper were similar to those obtained by Qi and co-workers for GCEs modified only by MWCNTs [30]. Because of that electrodes modified only with nanotubes were investigated using OSWV. These electrodes (GCE/SWCNT) showed peaks in similar positions as compared with electrodes with $\mathrm{Hb}(\mathrm{GCE} / \mathrm{SWCNT} / \mathrm{Hb})$. After immobilization of $\mathrm{Hb}$ peak observed with OSWV become smaller, what is in good agreement with results reported by Qi and co-workers [30] and probably indicate interaction of $\mathrm{Hb}$ with carboxylic groups of nanotubes. In the case of our experiments, these interaction caused decreasing of peak current deriving from $\mathrm{COOH}$, but not its disappearance.

After immobilization of $\mathrm{Hb}$ no peak appeared at negative potential when measured in solution saturated with argon. In solution containing small amount of oxygen (left in contact with air for some 
time after purging with argon) small peak appeared at about $-300 \mathrm{mV}$ connected probably with reduction of oxidized by oxygen hemoglobin. After purging the solution with inert gas, this peak disappeared. Such a phenomenon was not observed in the case of electrodes modified only with nanotubes (SWCNT/GCE).

We decided to check amperometric responses of electrodes modified with $\mathrm{Hb}$ (Hb/SWCNT/GCE) towards acrylamide and compare them with responses obtained for electrodes modified only with nanotubes (SWCNT/GCE).

\subsection{Amperometric responses of SWCNT/Hb modified glassy carbon electrode towards acrylamide.}

The determination of acrylamide by glassy carbon electrodes modified with single-walled carbon nanotubes and hemoglobin has been examined using two techniques: cyclic voltammetry (CV) and Osteryoung square wave voltammetry (OSWV) in solution containing $0.2 \mathrm{M}$ acetate buffer $\mathrm{pH} 5.0$ and $0.05 \mathrm{M} \mathrm{NaCl}$. OSWV technique (Figure 2) proved to be much more sensitive in comparison with $\mathrm{CV}$ (data not shown).

Figure 2. The OSWV curves for electrodes modified with $\mathrm{SWCNT} / \mathrm{Hb}$ measured in the presence of various concentrations of acrylamide. The electrolyte composition: $0.05 \mathrm{M}$ $\mathrm{NaCl}, 0.2 \mathrm{M}$ acetate buffer $\mathrm{pH}=5.0$. The concentration of analyte was, as follows: (A) 0 , (B) $1.0 \times 10^{-11}$, (C) $1.0 \times 10^{-10}$, (D) $1.0 \times 10^{-9}$, (E) $1.0 \times 10^{-8}$, (F) $1.0 \times 10^{-7}$, (G) $1.0 \times 10^{-6}$, (H) $1.0 \times 10^{-5}$, (I) $1.0 \times 10^{-4}$, (J) $1.0 \times 10^{-3} \mathrm{M}$.

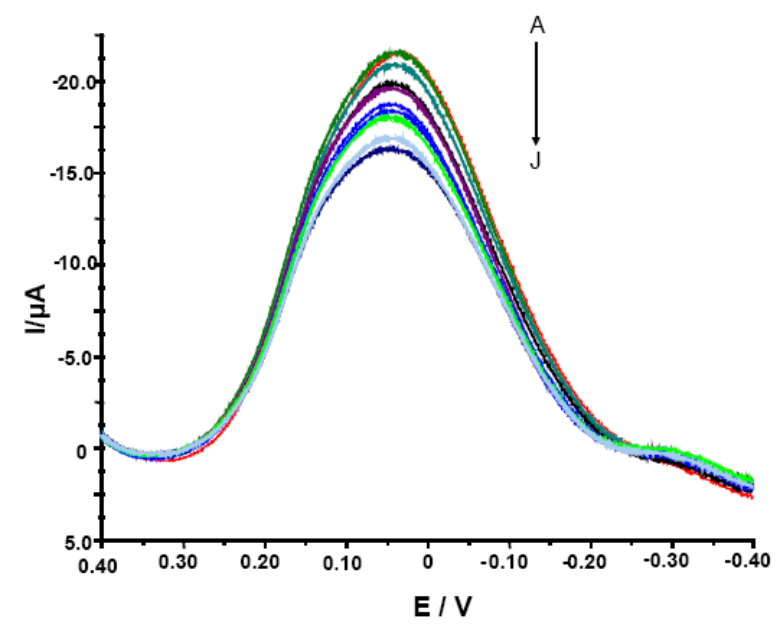

It was expected since the OSWV has the ability to suppress of background currents. Therefore, this method was more sensitive and more suitable for quantitative measurements [39, 40]. Electrodes modified with SWCNT/Hb showed various peak current (from -4.8 to $-21.6 \mu \mathrm{A}$ ) and peak potential (from 39.0 to $59.0 \mathrm{mV}$ ) in conditions of measurements and therefore, the parameter of relative decreasing of peak current was used to evaluate their responses. The ratio of OSWV peak current in the presence of different concentrations of acrylamide $\left(\mathrm{I}_{\mathrm{p}}\right)$ to that in the absence of analyte $\left(\mathrm{I}_{\mathrm{p}, 0}\right)\left(\mathrm{I}_{\mathrm{p}} / \mathrm{I}_{\mathrm{p}, 0} \mathrm{X}\right.$ $100 \%$ ) was plotted versus the acrylamide concentration. Even though the modified electrodes studied showed varied maximum current in measured solution, all of them displayed similar sensitivity 
towards acrylamide estimated with the use of the relative peak current decreasing $\left(\mathrm{I}_{\mathrm{p}} / \mathrm{I}_{\mathrm{p}, 0} \mathrm{x} 100 \%\right)$. Among numerous GCE/SWCNT/Hb studied, only 30\% displayed weak or no response towards the analyte and had to be rejected. This let us to state that reproducibility of proposed biosensor is good.

The linearity of $\mathrm{I}_{\mathrm{p}} / \mathrm{I}_{\mathrm{p}, 0} \times 100 \%$ versus $\log \mathrm{c}$ of acrylamide was observed in the concentration range from $1.0 \times 10^{-11}$ to $1.0 \times 10^{-3} \mathrm{M}$. The detection limit was estimated as $1.0 \times 10^{-9} \mathrm{M}$ taking into account a signal-to-noise ratio of 3 [41] and was low enough to detect acrylamide in food samples. Stobiecka and co-workers introduced a voltammetric sensor based on hemoglobin/DDAB liposomes dropped on the surface of carbon paste electrode [14]. These electrodes were used for detection of acrylamide in aqueous solution. Hemoglobin-acrylamide adducts were formed, what altered the electroactivity of hemoglobin and generated response of the biosensor. This biosensor displayed electrochemical response towards the analyte with similar linearity range of $1.3 \times 10^{-11}$ to $5.6 \times 10^{-3} \mathrm{M}$ and sensitivity in comparison to biosensor proposed in this paper.

As a control experiment electrodes modified only with acid treated SWCNTs were used These electrodes showed only negligible responses towards the analyte in the solution $\mathrm{pH}=5.0$ (Figure 3). This proved that the response generation only resulted from the presence of $\mathrm{Hb}$. The reaction of hemoglobin-acrylamide adducts formation alters the electroactivity of investigated system.

The electrodes modified with $\mathrm{Hb}$ were very stable. After preparation, they could be stored on air (at $4{ }^{\circ} \mathrm{C}$ ) ca. 2 weeks (a longer period was not explored). The interaction between $\mathrm{Hb}$ and acrylamide was irreversible. Therefore, after contact with acrylamide solution, the electrodes had to be cleaned and modified again. Because of this, the repeatability of investigated electrodes could not be estimated. However, the modification procedure was very simple, what is one of the most important advantages of presented biosensor.

Figure 3. The ratio of OSWV peak current in the presence of different concentration of acrylamide $\left(I_{p}\right)$ to that in the absence of acrylamide $\left(I_{p, 0}\right)$ as a function of the acrylamide concentration. The currents were measured at the peak potential in OSWV curves in the solution with no analyte $\mathrm{E}_{\mathrm{p}, 0}$. Results obtained for electrodes modified with SWCNT, $\mathrm{E}_{\mathrm{p}, 0}=46 \mathrm{mV}, \mathrm{n}=4,2.2<\mathrm{SD}<7.7(\diamond)$ and $\mathrm{SWCNT} / \mathrm{Hb}, \mathrm{E}_{\mathrm{p}, 0}=44 \mathrm{mV}, \mathrm{n}=3,0.9<\mathrm{SD}<4.4(\square)$.

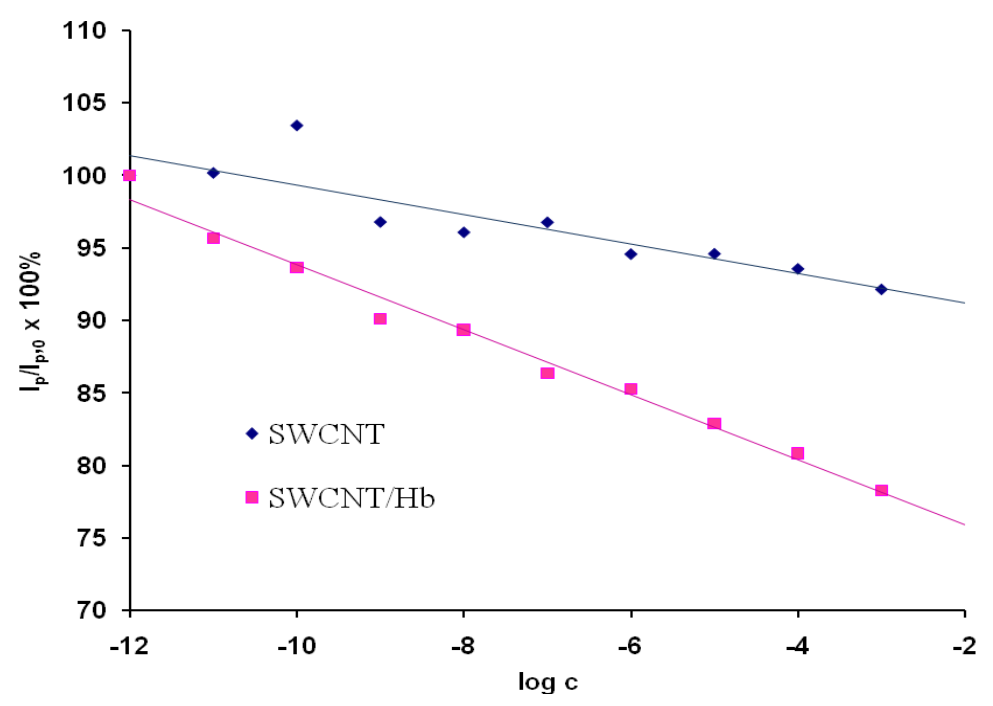


3.3. Detection of acrylamide in the presence of water extract from potato crisps using a glassy carbon electrode modified with hemoglobin

The applicability of the proposed sensor was tested using the OSWV technique, which was more sensitive than CV. The responses of the GCEs modified with SWCNT/Hb towards acrylamide were measured in the presence of sample solutions based on 100-fold diluted water extracts from potato crisps. The sample solution also contained 0.2 M acetate buffer ( $\mathrm{pH} 5.0$ ) and $0.05 \mathrm{M}$ of $\mathrm{NaCl}$. The relation of relative decreasing of peak current versus $\log \mathrm{c}$ was shown in Figure 4.

Figure 4. The response of $\mathrm{Hb} / \mathrm{SWCNT/GCE}$ electrodes towards acrylamide in the presence of water extract from the potato crisp. The ratio of OSWV peak current in the presence of a given concentration of acrylamide $\left(I_{\mathrm{p}}\right)$ to that in absence of analytes $\left(I_{\mathrm{p}, 0}\right)$ was plotted versus the concentration of acrylamide in water extract from the potato crisp. The currents were measured at the peak potential in OSWV curves in the solution with no analyte $\left(E_{\mathrm{p}, 0}=\right.$ $38 \mathrm{mV}) ;(n=3 ; 3.1<$ S.D. $<7.5)$.

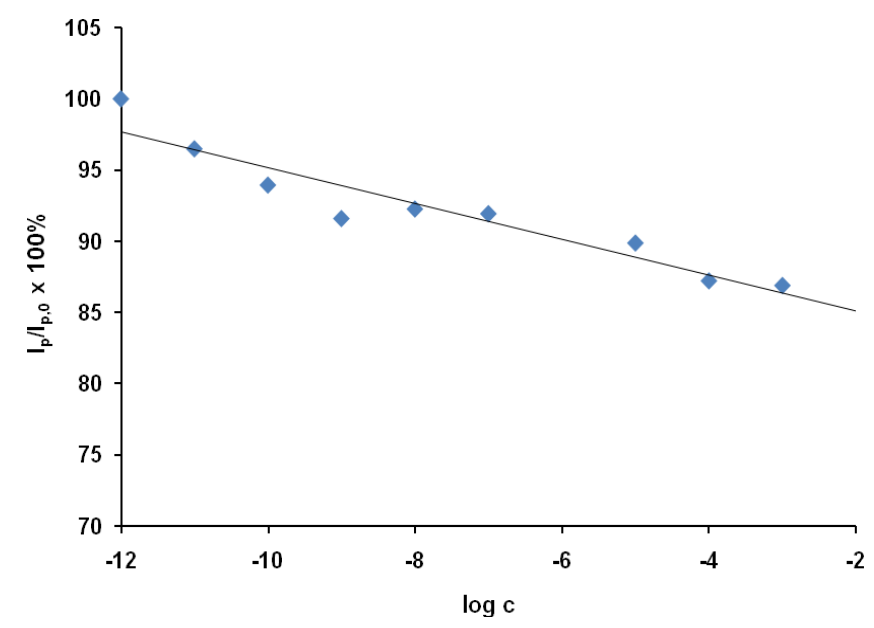

The electrodes modified only with SWCNT (without $\mathrm{Hb}$ ) responded towards the analyte weakly. $1 \mathrm{mM}$ acrylamide in the synthetic solution generated only $7.9 \pm 6.8 \%$ current decrease. Therefore this type of electrodes was not checked in the presence of the matrix.

The presence of the matrix obtained from potato influenced slightly on the electrode sensitivity towards acrylamide. The limit of detection estimated in the presence of the potato crisp matrix defined from a signal-to-noise ratio of 3 [41] was $1.0 \times 10^{-9} \mathrm{M}$. The linear range of this response was from $1.0 \times 10^{-11}$ to $1.0 \times 10^{-3} \mathrm{M}$.

There is no significant difference between analytical parameters of response towards acrylamide such as linear range or detection limit obtained for $\mathrm{Hb} / \mathrm{SWCNT/GCE}$ in aqueous solutions of acrylamide and in potato crisp extract, but the response measured in the synthetic solution was stronger. The highest acrylamide concentration studied $\left(1.0 \times 10^{-3} \mathrm{M}\right)$ caused $21.7 \pm 3.5 \%$ and $13.0 \pm$ $3.0 \%$ current decrease measured using OSWV, in the synthetic sample solution and in the potato crisps extract, respectively. 
A comparison of results obtained in the presence of the potato crisp matrix (Figure 4) with those obtained in synthetic solution (without the matrix - Figure 3), allows us to state that the sensor under study is resistant to interference coming from the matrix obtained by extraction of potato crisps. The next advantage is very good sensitivity in the $10^{-9} \mathrm{M}$ range. Also, the application of the proposed sensor for acrylamide determination does not require complex sample preparations.

The weak influence of the natural matrix on the electrodes sensitivity towards acrylamide proved their resistivity to interference coming from the potato crisps water extract. Thus it might be concluded that proposed biosensor can be used for determination of the level of acrylamide in such prepared extract.

\section{Conclusions}

Glassy carbon electrodes coated with SWCNT and Hb showed good voltammetric response towards acrylamide. The chemical base of the proposed biosensor is the formation of Hb-acrylamide adduct by the Michael-type nucleophilic addition reaction of a valine $-\mathrm{NH}_{2}$ group to the acrylamide double bond.

The observed redox reaction is not a diffusion, but rather a surface-controlled process. Observed redox peaks probably result from the $\mathrm{COOH}$ groups of SWCNTs, not from $\mathrm{Hb}$, but reaction of $\mathrm{Hb}-\mathrm{NH}_{2}$ with acrylamide alters the redox behaviour of the investigated system.

Osteryoung square wave voltammetry (OSWV) was more suitable for quantitative determination of acrylamide with electrodes presented than cyclic voltammetry $(\mathrm{CV})$. The presence of natural matrix obtained by water extraction from potato crisps influence only little on the acrylamide determination with glassy carbon electrode modified with hemoglobin. The biosensor display low detection limit $\left(10^{-9} \mathrm{M}\right)$ and wide dynamic range. Its preparation is relatively simple and inexpensive. Therefore, the proposed biosensor might be recommended for the direct determination of the acrylamide in the food samples.

\section{List of abbreviations:}

$\begin{array}{ll}\text { CNT } & \text { carbon nanotubes } \\ \text { CV } & \text { cyclic voltammetry } \\ \text { DDAB } & \text { dimethyldioctadecyl-ammonium bromide } \\ \text { DMF } & \text { dimethylformamide } \\ \text { EDC } & \text { 1-ethyl-3-(3-dimethylaminopropyl) carbodiimide } \\ \text { GCE } & \text { glassy carbon electrode } \\ \text { GCE/SWCNT/Hb } & \text { glassy carbon electrodes modified with single-walled carbon } \\ & \text { nanotubes and hemoglobin } \\ \text { GC-MS } & \text { gas chromatography-mass spectrometry } \\ \text { GC-MS-MS } & \text { gas chromatography-tandem mass spectrometry } \\ \text { Hb } & \text { hemoglobin } \\ \text { HPLC-MS } & \text { high-performance liquid chromatography-mass spectrometry }\end{array}$




\begin{tabular}{|c|c|}
\hline LC-MS-MS & liquid chromatography- tandem mass spectrometry \\
\hline MWCNTs & multiwall carbon nanotubes \\
\hline Nafion-Hb-CNT/GCE & $\begin{array}{l}\text { glassy carbon electrode modified with carbon nanotubes, } \\
\text { hemoglobin and Nafion }\end{array}$ \\
\hline OSWV & Osteryoung square wave voltammetry \\
\hline QCM & quartz crystal microbalance \\
\hline SCE & saturated calomel electrode \\
\hline SWCNT-COOH & acid treated single-walled carbon nanotubes \\
\hline SWCNTs & single-walled carbon nanotubes \\
\hline
\end{tabular}

\section{Acknowledgements}

The work presented was supported by the grant of Polish Ministry of Science and Higher Education No. 2PO6T08827, NATO project CBP.NR.CLG.982211 and the Institute of Animal Reproduction and Food Research, Polish Academy of Sciences, Olsztyn, Poland.

\section{References}

1. Tareke, E.; Rydberg, P.; Karlsson, P.; Eriksson, S.; Törnqvist, M. Analysis of acrylamide, a carcinogen formed in heated foodstuffs. J. Agric. Food Chem. 2002, 50, 4998-5006.

2. Ruden, C. Acrylamide and cancer risk - export risk assessments and the public debate. Food Chem. Toxicol. 2004, 42, 335-349.

3. Friedman, M. Chemistry, biochemistry and safety of acrylamide. A review. J. Agric. Food Chem. 2003, 51, 4504-4526.

4. Gökmen, V.; Şenyuva, H.Z.; Acar, J.; Sarıoglu, K. Determination of acrylamide in potato chips and crisps by high-performance liquid chromatography. J. Chrom. A 2005, 1088, 193-199.

5. Becalski, A.; Lau, B.P.-Y.; Lewis, D.; Seaman, S.W. Acrylamide in foods: occurrence, sources and modelling. J. Agric. Food Chem. 2003, 51, 802-808.

6. Mottram, D.S.; Wedzicha, B.L.; Dodson, A.T. Acrylamide is formed in the Maillard reaction. Nature 2002, 419, 448-449.

7. Stadler, R.H.; Blank, I.; Varga, N.; Robert, F.; Hau, J.; Guy, P.A.; Robert, M.-C.; Riediker, S. Acrylamide from Maillard reaction products. Nature 2002, 419, 449.

8. Zyzak, D.V.; Sanders, R.A.; Stojanovic, M.; Tallmadge, D.H.; Eberhart, B.L.; Ewald, D.K.; Gruber, D.C.; Morsch, T.R.; Strothers, M.A.; Rizzi, G.P.; Villagran, M.D. Acrylamide formation mechanism in heated foods. J. Agric. Food Chem. 2003, 51, 4782-4787.

9. Mizukami, Y.; Kohata, K.; Yamaguchi, Y.; Hayashi, N.; Sawai, Y.; Chuda, Y.; Ono, H.; Yada, H.; Yoshida, M. Analysis of acrylamide in green tea by gas chromatography-mass spectrometry. $J$. Agric. Food Chem. 2006, 54, 7370-7377.

10. Hoenicke, K.; Gatermann, R.; Harder, W.; Hartig, L. Analysis of acrylamide in different foodstuffs using liquid chromatography-tandem mass spectrometry and gas chromatographytandem mass spectrometry. Anal. Chim. Acta 2004, 520, 207-215. 
11. Robert, F.; Vuataz, G.; Pollien, P.; Saucy, F.; Alonso, M.-I.; Bauwens, I.; Blank, I. Acrylamide firmation from asparagine under low moisture Maillard reaction conditions. 2. Crystalline vs amorphous model systems. J. Agric. Food Chem. 2005, 53, 4628-4632.

12. Ignatov, O.V.; Rogatcheva, S.M.; Kozulin S.V.; Khorkina N.A. Acrylamide and acrylic acid determination using respiratory activity of microbial cells. Biosens. Bioelectron. 1996, 12, 105-111.

13. Kleefish, G.; Kreutz, C.; Bargon, J.; Silva, G.; Schalley, C. A. Quartz microbalance sensor for the detection of acrylamide. Sensors 2004, 4, 136-146.

14. Stobiecka, A.; Radecka, H.; Radecki, J. Novel voltammetric biosensor for determining acrylamide in food samples. Biosens. Bioelectron. 2007, 22, 2165-2170.

15. Scheller, F.W.; Bistolas, N.; Liu, S., Janchen, M.; Katterle, M.; Wollenberger, U. Thirty years of haemoglobin electrochemistry. Adv. Colloid. Interface Sci. 2005, 116, 111-120.

16. Hagmar, L.; Wirfält, E.; Paulsson, B.; Törnqvist, M. Differences in hemoglobin adduct levels of acrylamide in the general population with respect to dietary intake, smoking habits and gender. Mutat. Res. 2005, 580, 157-165.

17. Paulsson, B.; Grawe, J.; Törnqvist, M. Hemoglobin adducts and micronucleus frequencies in mouse and rat after acrylamide or N-methylolacrylamide treatment. Mutat. Res. 2002, 516, 101-111.

18. Luo, X.; Morrin, A.; Killard, A.J.; Smyth, M.R. Application of nanoparticles in electrochemical sensors and biosensors. Electroanalysis 2006, 18, 319-326.

19. Wang, J. Nanoparticle-based electrochemical bioassays of proteins. Electroanalysis 2007, 19, 769-776.

20. Luo, H.; Shi, Z.; Li, N.; Gu, Z.; Zhuang, Q. Investigation of the electrochemical and electrocatalytic behavior of single-wall carbon nanotube film on a glassy carbon electrode. Anal. Chem. 2001, 73, 915-920.

21. Yin, Y.; Lü, Y.; Wu, P.; Cai, C. Direct electrochemistry of redox proteins and enzymes promoted by carbon nanotubes. Sensors 2005, 5, 220-234.

22. Yang, M.; Qu, F.; Li, Y.; He, Y.; Shen, G.; Yu, R. Direct electrochemistry of hemoglobin in gold nanowire array. Biosens. Bioelectron. 2007, 23, 414-420.

23. Gu, H.-Y.; Yu, A.-M.; Chen, H.-Y. Direct electron transfer and characterization of hemoglobin immobilized on a Au colloid-cysteamine-modified gold electrode. J. Electroanal. Chem. 2001, 516, 119-126.

24. Zhang, L.; Jiang, X.; Wang, E.; Dong, S. Attachment of gold nanoparticles to glassy carbon electrode and its application for the direct electrochemistry and electrocatalytic behavior of hemoglobin. Biosens. Bioelectron. 2005, 21, 337-345.

25. Han, X.; Cheng, W.; Zhang, Z.; Dong, S.; Wang, E. Direct transfer between hemoglobin and a glassy carbon electrode facilitated by lipid-protected gold nanoparticles. Biochim. Biophys. Acta 2002, 1556, 273-277.

26. Wang, C.; Yang, C.; Song, Y.; Gao, W.; Xia, X. Adsorption and direct electron transfer from hemoglobin into a three-dimensionally ordered macroporous gold film. Adv. Funct. Mater. 2005, 15, 1267-1275. 
27. Wang, Y.; Qian, W.; Tan, Y.; Ding, S.; Zhang, H. Direct electrochemistry and electroanalysis of hemoglobin adsorbed in self-assembled films of gold nanoshells. Talanta 2007, 72, 1134-1140.

28. Chen, S.; Yuan, R.; Chai, Y.; Zhang, L.; Wang, N.; Li, X. Amperometric third-generation hydrogen peroxide biosensor based on the immobilization of hemoglobin on multiwall carbon nanotubes and gold colloidal nanoparticles. Biosens. Bioelectron. 2007, 22, 1268-1274.

29. Zhang, R.; Wang, X.; Shiu, K.-K. Accelerated direct electrochemistry of hemoglobin based on hemoglobin-carbon nanotube (Hb-CNT) assembly. J. Colloid Interface Sci. 2007, 316, 517-522.

30. Qi, H.; Zhang, C.; Li, X. Amperometric third-generation hydrogen peroxide biosensor incorporating multiwall carbon nanotubes and hemoglobin. Sens. Actuators, B 2006, 114, 364-370.

31. Zhang, Y.; Cheng, W.; Li, S.; Li, N. Direct electron transfer of hemoglobin on DDAB/SWNTs film modified Au electrode and its interaction with Taxol. Colloids Surf., A 2006, 286, 33-38.

32. Yang, P.; Zhao, Q.; Gu, Z.; Zhuang, Q. The electrochemical behavior of hemoglobin on SWNTs/DDAB film modified glassy carbon electrode. Electroanalysis 2004, 16, 97-100.

33. Ma, G.-X.; Wang, Y.-G.; Wang, C.-X.; Lu, T.-H.; Xia, Y.-Y. Hemoglobin immobilized on whisker-like carbon composites and its direct electrochemistry. Electrochim. Acta 2008, 53, 47484753.

34. Iijima, S. Carbon nanotubes: past, present, and future. Physica B 2002, 323, 1-5.

35. Goyanes, S.; Rubiolo, G.R.; Salazar, A.; Jimeno, A.; Corcuera, M.A.; Mondragon, I. Carboxylation treatment of multiwalled carbon nanotubes monitored by infrared and ultraviolet spectroscopies and scanning probe microscopy. Diamond Relat. Mater. 2007, 16, 412-417.

36. Su, S.-H.; Chiang, W.-T.; Lin, C.-C.; Yokoyama, M. Multi-wall carbon nanotubes: Purification, morphology and field emission performance. Physica E 2008, 40, 2322-2326.

37. Profumo, A.; Fagnoni, M.; Merli, D.; Quartarone, E.; Protti, S.; Dondi, D.; Albini, A. Multiwalled carbon nanotubes chemically modified gold electrode for inorganic as apeciation and $\mathrm{Bi}(\mathrm{III})$ determination. Anal. Chem. 2006, 78, 4194-4199.

38. Bard, A.J.; Faulkner, L.R. In Electrochemical methods. Fundamentals and applications. John Wiley and sons, Inc.: New York, 2001

39. Osteryoung, J. Voltammetry for the future. Acc. Chem. Res. 1993, 26, 77-83.

40. Osteryoung, J.G.; Osteryoung, R.A. Square wave voltammetry. Anal. Chem. 1985, 57, 101A110A.

41. Fan, C.; Liu, X.; Pang, J.; Li, G.; Scheer, H. Highly sensitive voltammetric biosensor for nitric oxide based on its high affinity with hemoglobin. Anal. Chim. Acta 2004, 523, 225-228.

(C) 2008 by the authors; licensee Molecular Diversity Preservation International, Basel, Switzerland. This article is an open-access article distributed under the terms and conditions of the Creative Commons Attribution license (http://creativecommons.org/licenses/by/3.0/). 